\title{
Effects of Transformation Strain Due to Lithiation/delithiation in Sn Electrode of Li-ion Batteries
}

\author{
Tetsu Ichitsubo,* Kousuke Hirai, Shunsuke Yukitani, and Eiichiro Matsubara
}

\begin{abstract}
Department of Material Science and Engineering, Kyoto University (Yoshidahon-machi, Sakyo-ku, Kyoto 606-8501, Japan)
\end{abstract}

Received January 14, 2010 ; Accepted January 28, 2010

\begin{abstract}
Sn and Sn-based compounds have attracted great interest as a candidate for anode materials of Li-ion batteries. In the present work, in a Sn-Li battery system we have investigated effects of the volume change associated with the formation of Li-Sn compounds on the electrode potential from the viewpoint of the Gibbs free energy and associated elastic-strain energy. Our experimental results show that the experimental electrode potential is much lower than the value expected thermodynamically, when a Sn plate-shape electrode is lithiated. These experimental results can be consistently explained by considering the contribution of the elastic-strain energy to the chemical free energy of formation.
\end{abstract}

Key Words : Li-ion Battery, Sn Electrode, $\beta$-Sn, Strain Energy, Electrode Potential

\section{Introduction}

Lithium-ion battery is currently used for batteries of various mobile electronic devices, such as mobile phones and laptops. Though carbon is commonly used as an active anode material of lithium-ion batteries, its capacity has already reached the theoretical value.1) Thus, alternative materials exhibiting a larger capacity have been required for the future applications, such as plug-in hybrid EV and EV, etc. Sn and Sn-based alloys or their composites have attracted much interest as one of the high capacity anode materials. ${ }^{2-5)}$

Sn forms several kinds of compounds with Li as summarized in Table $1 . \mathrm{Li}_{22} \mathrm{Sn}_{5}$ is, for example, the compound of the highest Li concentration whose theoretical capacity

Table 1 The Li-Sn compounds, molar volumes, volume expansions, and specific capacities.

\begin{tabular}{ccccc}
\hline Compounds & $\begin{array}{c}p \text { value } \\
\left(\mathrm{Li}_{p} \mathrm{Sn}\right)\end{array}$ & $\begin{array}{c}\text { Molar volume } \\
\Omega / 10^{-6} \mathrm{~m}^{3} \mathrm{~mol}^{-1}\end{array}$ & $\begin{array}{c}\text { expansion } \\
\text { expacity/ }\end{array}$ & $\begin{array}{c}\text { Capact } \\
\text { Ahkg }^{-1}\end{array}$ \\
\hline$\beta-\mathrm{Sn}$ & - & 16.3 & 1.00 & - \\
$\mathrm{Li}_{2} \mathrm{Sn}_{5}$ & 0.4 & 19.9 & 1.22 & 90.3 \\
$\mathrm{LiSn}$ & 1.0 & 24.6 & 1.51 & 225.8 \\
$\mathrm{Li}_{7} \mathrm{Sn}_{3}$ & 2.3 & 36.8 & 2.26 & 526.8 \\
$\mathrm{Li}_{5} \mathrm{Sn}_{2}$ & 2.5 & 38.4 & 2.36 & 564.4 \\
$\mathrm{Li}_{3} \mathrm{Sn}_{5}$ & 2.6 & 39.5 & 2.43 & 587.0 \\
$\mathrm{Li}_{7} \mathrm{Sn}_{2}$ & 3.5 & 48.3 & 2.97 & 790.2 \\
$\mathrm{Li}_{22} \mathrm{Sn}_{5}$ & 4.4 & 58.3 & 3.58 & 993.4 \\
\hline
\end{tabular}

The volume denotes value per one mole of $\mathrm{Sn}$ atom and is calculated by dividing the unit cell volume with the number of only $\mathrm{Sn}$ atoms without taking account of the number of $\left.\mathrm{Li}^{7}{ }^{7}\right)$ The volume expansion is the value obtained by dividing each volume with the volume of $\beta$-Sn, and the capacity is defined as electronic quantity per unit weight of Sn to transform into each Li-Sn compounds. becomes about $990 \mathrm{Ah} / \mathrm{kg}$ that is far greater than that of carbon. ${ }^{6)}$ Despite of this excellent property of Sn-based alloys, they cannot be alternatively used for carbon at present because of serious degradation in cycle characteristic due to a large volume change during the battery reaction. For example, the volume of $\mathrm{Li}_{22} \mathrm{Sn}_{5}$ per $\mathrm{Sn}$ atom is about three times larger than that of Sn (see Table 1). ${ }^{7)}$ Although many extensive works on Sn anode have been carried out, there are little systematic studies about the effect of a volume change on the structural transformation of Sn and the electrode potential. In the present work, the effect of the volume change of $\mathrm{Sn}$ in accompanied with lithiation on the electrode potential was evaluated from the viewpoint of the Gibbs free energy and elastic-strain energy associated with the formation of a Li-Sn compound in Sn matrix.

\section{Experimental}

A simple Li-Sn cell consisting of $\mathrm{Sn}$ cathode and $\mathrm{Li}$ anode was used. For an electrolyte, $1 \mathrm{M} \mathrm{LiPF}_{6}$ in a solution of $33 \%$ ethylene carbonate and $67 \%$ dimethyl carbonate was used. The cells were assembled in an argonfilled glove box and all charge-discharge experiments were performed at room temperature.

A plate-shaped Sn electrode, with a weight of $0.044 \mathrm{~g}$, a thickness of $30 \mu \mathrm{m}$, and a diameter of $16 \mathrm{~mm}$, was used in the experiment. After the cell was partially discharged (i.e., the Sn cathode is lithiated in the present case) to a certain amount of Li by passing current at about 0.60 $\mathrm{Am}^{-2}$, the electrode potential was measured under the open circuit condition (i.e., at zero current) as a function of rest time. The rest time denotes the elapsed time under the open circuit state. The maximum capacity of $\mathrm{Li}$ in the open circuit voltage $(\mathrm{OCV})$ measurements was set at $90.3 \mathrm{Ah} / \mathrm{kg}$ that is the amount of Li for transformation of the entire $\mathrm{Sn}$ electrode to $\mathrm{Li}_{2} \mathrm{Sn}_{5}$ in the reaction of $5 \mathrm{Sn}+2 \mathrm{Li} \rightarrow \mathrm{Li}_{2} \mathrm{Sn}_{5}$. We measured the OCV values and 
their time-dependence in order to observe the structure transformation in the Sn electrode affected by the elastic strain during the lithiation and discuss the compound formation kinetics, because the electrode potential in the open circuit condition corresponds to the equilibrium value excluding the other effects, such as IR drop.

For X-ray diffraction measurement with MoKo, the Sn electrode after lithiation of $p=0.89$ was sealed with a Kapton window in an Ar atmosphere.

\section{Results}

Figure 1 shows the electrode potential as a function of rest time at various capacities. The percentages in the figure correspond to the capacities when the maximum capacity for $p=0.4\left(90.3 \mathrm{Ah} \mathrm{kg}^{-1}\right)$ is set at $100 \%$. Two plateaus appear at about 0.53 and $0.66 \mathrm{~V}$ in the OCV-time curves. The OCV values at the first and second plateaus are almost the same irrespective of the lithiation capacities, respectively. The appearance of the second plateau is clearly retarded with increase in the capacity. In the curve over $100 \%$, the second plateau cannot be detected within the present experimental time of 30 hours. As it was mentioned above, in the preset capacity in Fig. 1, the $\mathrm{Sn}$ electrode is in the two phase region of pure $\mathrm{Sn}$ and $\mathrm{Li}_{2} \mathrm{Sn}_{5}$ and the OCV value at the second plateau is supposed to be the thermodynamically evaluated value $\left(0.777 \mathrm{~V}\right.$ vs. $\left.\left.\mathrm{Li}^{+} / \mathrm{Li}\right)\right)^{8)}$ The OCV value of $0.66 \mathrm{~V}$ is, however, considerably lower.

These intriguing results, i.e., (i) the $\mathrm{OCV}$ values much lower than the $\mathrm{Sn} / \mathrm{Li}_{2} \mathrm{Sn}_{5}$ equilibrium value and (ii) the presence of the two plateaus, cannot be explained by the diffusion limit of $\mathrm{Li}$ in $\mathrm{Sn}$ matrix, since the diffusion rate expected from the diffusion coefficient ${ }^{2}$ of the order $10^{-8}$ $\mathrm{cm}^{2} \mathrm{~s}^{-1}$ is sufficiently higher than the lithiation rate of $0.60 \mathrm{~A} \mathrm{~m}^{-2}$ in the present experimental condition.

Because of the presence of the first plateau, it is expected that the LiSn $(p=1)$ compound with a higher Li composition is formed though the amount of lithiation in Fig. 1 is only 10-50 $\mathrm{Ah} \mathrm{kg}^{-1}(p<0.4)$ far less than $225.8 \mathrm{Ah} \mathrm{kg}^{-1}$ that is the capacity for the formation of LiSn. The OCV values in Fig. 1 recover with rest time despite the open circuit condition, which indicates that the internal structure of the electrode material changes with time. Namely, the $\mathrm{Li}$ rich phase, i.e. LiSn, which is likely to be formed near the surface, vanishes due to the diffusion of $\mathrm{Li}$ into

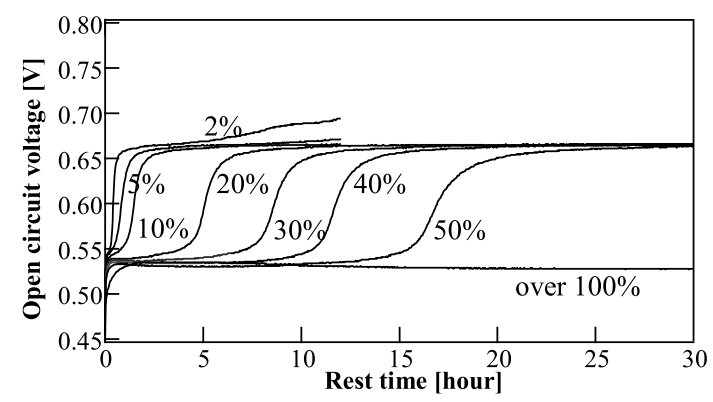

Fig. 1 The curves of OCV as a function of rest time at various capacities. In this figure, the maximum capacity (90.3 $\mathrm{Ah} \mathrm{kg}^{-1}$ ) in the reaction of $5 \mathrm{Sn}+2 \mathrm{Li} \rightarrow \mathrm{Li}_{2} \mathrm{Sn}_{5}$ is considered as a standard (i.e., $100 \%$ when $p=0.4$ ).

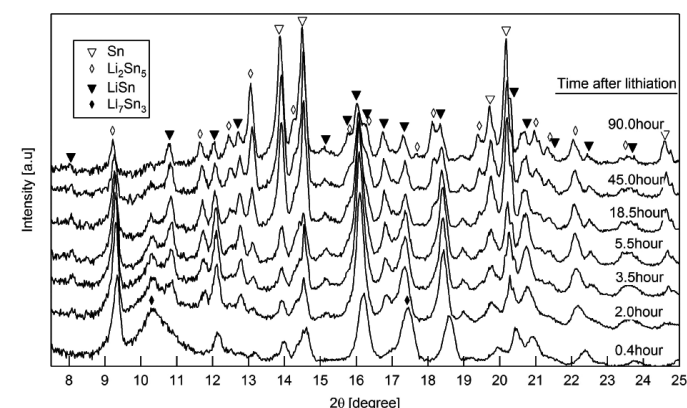

Fig. 2 Change of X-ray diffraction profiles of the Sn electrode after lithiation of $p=0.89$ against $\mathrm{Sn}$. In this $\mathrm{Li}$ concentration, the compounds of $\mathrm{Li}_{2} \mathrm{Sn}_{5} / \mathrm{LiSn}$ are the thermodynamically equilibrium phases.

the inner side, and the electrode is eventually occupied with $\mathrm{Sn}$ and $\mathrm{Li}_{2} \mathrm{Sn}_{5}$, leading to the equilibrium state.

In the case of $p=0.89$, observation of X-ray diffraction profiles in Fig. 2 shows the presence of the compound $\mathrm{Li}_{7} \mathrm{Sn}_{3}(p=2.3)$ with higher Li composition. Also, in Fig. 2, the $\mathrm{Li}_{7} \mathrm{Sn}_{3}$ phase gradually disappears with time and the structure of the electrode is transformed towards the equilibrium phases of $\mathrm{Li}_{2} \mathrm{Sn}_{5}$ and $\mathrm{LiSn}$.

\section{Discussion}

The lower OCV values at the plateaus are explained by considering the effect of elastic strain due to a volume change in the structure transformation with the lithiation. The elastic-strain energy can be estimated, using the micromechanics theory based on Eshelby's ellipsoidal inclusion theory. The calculation procedure and the physical properties used in the present calculation are described in Refs. 9-13.

The elastic strain inside the inclusion is given by

$$
\varepsilon_{i j}=\gamma_{i j}-\varepsilon_{i j}^{*}
$$

where $\gamma$ and $\varepsilon^{*}$ are the total strain and eigenstrain (i.e. stress-free transformation strain), respectively. In the present case, it is assumed that an isolated spherical LiSn compound is formed within a Sn matrix, and $\varepsilon^{*}$ represents the average eigenstrain determined from the volume per mole of Sn atom in the substance, whose nonzero components are approximately given by

$$
\varepsilon_{11}^{*}=\varepsilon_{22}^{*}=\varepsilon_{33}^{*}=\left(\sqrt{\Omega}_{I}-3 \sqrt{\Omega}_{M}\right) /{ }^{3} \sqrt{\Omega}_{M}
$$

In this equation, subscript " $M$ " and " $I$ " denote the matrix and the inclusion, respectively. The elastic-strain energy $U_{\mathrm{s}}$ of the system including an isolated inclusion with volume $\Omega$ is given by

$$
U_{\mathrm{s}}=-\frac{1}{2} C_{i j k l}\left(\gamma_{k l}-\varepsilon_{k l}^{*}\right) \varepsilon_{i j}^{*} \Omega
$$

For example, in the case of the $\mathrm{Li}_{2} \mathrm{Sn}_{5}$ formation in $\mathrm{Sn}$, the eigenstrain $\varepsilon^{*}$ is 0.069 , and the molar volume $\Omega_{\mathrm{M}}(=$ $16.3 \times 10^{-6} \mathrm{~m}^{3} \mathrm{~mol}^{-1}$ ) of the Sn matrix should be used for $\Omega$; then $U_{\mathrm{s}}$ is calculated to be $U_{\mathrm{s}}=9.63 \mathrm{~kJ} \mathrm{~mol}^{-1}$. Under such an elastically constrained condition, the electrode 
Table 2 Formation reaction of various LiSn compounds and corresponding electrode potential.

\begin{tabular}{lccccc}
\hline Lithiation reaction & $\begin{array}{c}\text { Electrode potential } \\
\left.E_{\text {chem }} / \mathrm{V} \text { [vs. Li } / \mathrm{Li}\right]\end{array}$ & $\begin{array}{c}\text { Eigenstrain } \\
\varepsilon^{*}\end{array}$ & $\begin{array}{c}\text { Strain energy } \\
U_{\mathrm{s}} / \mathrm{kJ} \mathrm{mol}^{-1}\end{array}$ & $\begin{array}{c}\text { Potential drop } \\
\Delta E / \mathrm{V}\end{array}$ & $\begin{array}{c}\text { Electrode potential } \\
\left.E_{\text {total }} / \mathrm{V} \text { [vs. } \mathrm{Li}^{+} / \mathrm{Li}\right]\end{array}$ \\
\hline$(2 / 5) \mathrm{Li}+\mathrm{Sn}=(1 / 5) \mathrm{Li}_{2} \mathrm{Sn}_{5}$ & 0.777 & 0.069 & 9.63 & 0.250 & 0.528 \\
$(3 / 5) \mathrm{Li}+(1 / 5) \mathrm{Li}_{2} \mathrm{Sn}_{5}=\mathrm{LiSn}$ & 0.690 & 0.074 & 13.6 & 0.235 & 0.455 \\
$(4 / 3) \mathrm{Li}+\mathrm{LiSn}=(1 / 3) \mathrm{Li}_{7} \mathrm{Sn}_{3}$ & 0.448 & 0.14 & 62.6 & 0.487 & -0.039 \\
$(1 / 6) \mathrm{Li}+(1 / 3) \mathrm{Li}_{7} \mathrm{Sn}_{3}=(1 / 2) \mathrm{Li}_{5} \mathrm{Sn}_{2}$ & 0.446 & 0.015 & 1.03 & 0.064 & 0.382 \\
$(1 / 10) \mathrm{Li}+(1 / 2) \mathrm{Li}_{5} \mathrm{Sn}_{2}=(1 / 5) \mathrm{Lil}_{3} \mathrm{Sn}_{5}$ & 0.439 & 0.0094 & 0.42 & 0.044 & 0.395 \\
$(9 / 10) \mathrm{Li}+(1 / 5) \mathrm{Li}_{3} \mathrm{Sn}_{5}=(1 / 2) \mathrm{Li}_{7} \mathrm{Sn}_{2}$ & 0.437 & 0.069 & 23.6 & 0.272 & 0.165 \\
$(9 / 10) \mathrm{Li}+(1 / 2) \mathrm{Li}_{7} \mathrm{Sn}_{2}=(1 / 5) \mathrm{Li}_{22} \mathrm{Sn}_{5}$ & 0.426 & 0.065 & 25.2 & 0.290 & 0.135 \\
\hline
\end{tabular}

* The electrode potentials, $E_{\text {chem }}$, are calculated from the thermodynamic data reported in Ref. 8.

potential $E_{\text {total }}$ can be rewritten as

$$
E_{\text {total }}=\frac{\Delta G_{\text {chem }}+U_{\mathrm{s}}}{n F}=E_{\text {chem }}-\Delta E
$$

Where $\Delta G_{\text {chem }}$ is the Gibbs free energy of the formation per one mole of Sn, the value of $n$ is $2 / 5$ for the first lithiation reaction, and $3 / 5$ for the second reaction, etc.

The strain energy $U_{\mathrm{s}}$ and the value of the potential drop $\Delta E$ are also shown in Table 2 for all the reactions. It is seen in Table 2 that the electrode potential (OCV) is considerably lowered by the strain energy. It is also noted that the elastic strain induced by the formation of the Li-Sn compound is much larger than the tensile strength of Sn matrix. Thus, in the actual electrode, the matrix around the compound is under the creep deformation and releases the strain. The experimental OCV value of 0.66 in Fig. 1, for example have the value between the thermodynamically evaluated value of $0.777 \mathrm{~V}$ and the value calculated from the eigenstrain in Table 2.

When the Li-Sn compounds are formed on the electrode surface, most of the large elastic strain energy by the compound formation is easily released. Thus, the effect of the strain energy on the free energy of the compound formation becomes larger with the distance from the electrode surface. By considering that the compound are successively formed along the depth, at a certain point, the formation of the $\mathrm{Li}-\mathrm{Sn}$ compound with a higher Li composition such as LiSn on the surface is thermodynamically more favorable than the formation of the Li-Sn compound with less Li inside of the electrode. This actually happens in the electrode of Fig. 1 where the LiSn compound with a higher Li composition is formed though the amount of lithiation is far less than the capacity for the formation of LiSn.

Additionally, once such a Li-rich compound is formed, the creep deformation of the matrix inevitably occurs, and it is well accommodated in the matrix. Consequently, $\mathrm{Li}$ atoms are very difficult to be desorbed from the Lirich compounds, because the volume shrinking is accompanied by this reaction, negative hydrostatic pressure is applied to the compound, leading to the appearance of the very stable plateaus due to the non-equilibrium Lirich compound. This is case where the time retardation occurs with the capacity in Fig. 1. The OCV profile of the capacity over $100 \%$ is the extreme case.

\section{Conclusion}

By using a simple Li-Sn cell, we have investigated the effects of the elastic-strain energy accompanied with the phase transformation through the lithiation and delithiation process. The electrode potential curves of the Sn electrode which partially lithiated have two plateaus and appearance of the latter is retarded with time. These experimental results can be explained by considering the effects of the elastic-strain energy to the Gibbs free energy of formation. It has been revealed that the elastic strain associated with the formation of a new phase accompanying a volume change causes the formation of the Li-rich compound and affects the value of the electrode potential considerably.

\section{Acknowledgement}

This work is partly supported by Grant-in-Aid for "Fundamental Scientific Research Project on Advanced Storage Batteries" from NEDO, Japan.

\section{References}

1) L. Y. Beaulieu, D. Larcher, R. A. Dunlap, and J. R. Dahn, J. Electrochem. Soc., 147, 3206 (2000).

2) R. A. Huggins, J. Power Sources, 81-82, 13 (1999).

3) J. Wang, I. D. Raistrick, and R. A. Huggins, J. Electrochem. Soc., 133, 457 (1986).

4) O. Mao, R. A. Dunlap, and J. R. Dahn, J. Electrochem. Soc., 146, 405 (1999).

5) I. A. Courtney and J. R. Dahn, J. Electrochem. Soc., 144, 2045 (1997).

6) M. Winter and J. O. Besenhard, Electrochim. Acta, 45, 31 (1999).

7) C. Yu, J. Liu, H. Lu, and J. Chen, Solid State Commun., 140, 538 (2006).

8) F. Yin, X. Su, Z. Li, and J. Wang, J. Alloys and Compounds, 393, 105 (2005).

9) K. Hirai, T. Ichitsubo, T. Uda, A. Miyazaki, S. Yagi, and E. Matsubara, Acta Mater., 56, 1539 (2008).

10) T. Ichitsubo, M. Nakamoto, K. Tanaka, and M. Koiwa, Mater. Trans. JIM, 39, 24 (1998).

11) T. Ichitsubo, K. Tanaka, M. Koiwa, and Y. Yamazaki, Phys. Rev. B, 62, 5435 (2000).

12) T. Nakamura, T. Ichitsubo, E. Matsubara, A. Muramatsu, N. Sato, and H. Takahashi, Acta Mater., 53, 323 (2005).

13) N. Usami, T. Ichitsubo, T. Ujihara, T. Takahashi, K. Fujiwara, G. Sazaki, and K. Nakajima, J. Appl. Phys., 94, 916 (2003). 